\title{
The sleeping giant: Case report on central giant cell granuloma of maxilla
}

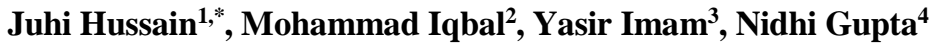 \\ ${ }^{1}$ Senior Lecturer, ${ }^{2}$ Reader, ${ }^{3}$ Registrar Endodontist, ${ }^{4} \mathrm{PG}$ Student, ${ }^{1}$ Dept. of Oral Medicine \& Radiology, ${ }^{\mathbf{2}, \mathbf{3}}$ Dept. of Conservative \\ Dentistry, ${ }^{4}$ Dept. of Periodontology, ${ }^{1,2,4}$ Rama Dental College, Hospital \& Research Centre, Kanpur, Uttar Pradesh, India, ${ }^{3}$ Central \\ Security Hospital, Saudi Arab \\ *Corresponding Author: \\ Email: juhihussain@yahoo.com
}

\begin{abstract}
Central Giant Cell Granuloma (CGCG), first described by Jaffe in 1953 is a non neoplastic, reactive lesion of unknown etiology which commonly occurs in the Mandible but can occur in Maxilla also. The radiographic appearance of this lesion is not consistent and may at times lead to incorrect diagnosis. We present a case of Central Giant Cell Granuloma of the Anterior Maxilla and highlight the importance of radiographic investigations in the diagnosis of such lesions.
\end{abstract}

Keywords: Giant Cells, Maxilla, Granuloma.

\section{Introduction}

According to the World Health Organization, Central giant cell granuloma has been defined as "an intraosseous lesion consisting of cellular fibrous tissue that contains multiple foci of hemorrhage, aggregations of multinucleated giant cells and occasionally trabeculae of woven bone". ${ }^{1}$ The etiology of Central Giant Cell Granuloma is not clear but it has been proposed that it may occur from trauma or vascular insult producing Intramedullary Hemorrhage. If the blood supply is cut off completely, no giant cell reaction occurs and traumatic bone cyst results. If the blood supply is fully maintained, an Arteriovenous Malformation develops. If the blood supply is maintained partially then an Aneurysmal Bone Cyst or Central Giant Cell Granuloma may form. Radiographic investigations hold key importance in the diagnosis of such a lesion. ${ }^{2}$

Central Giant Cell Granuloma has a predilection for females than males and occurs most frequently in children or young adults. Also, it usually occurs in the mandible than the maxilla. ${ }^{1}$

Central Giant Cell Granuloma has been categorized as Aggressive and Non Aggressive. Aggressive lesions affect patients younger than 20 years of age and are fast growing, often painful. Non Aggressive lesions affect patients more than 20 years of age and are slow growing and not painful. Recurrence rate is less in non aggressive lesions. The radiographic differentiating feature of both forms is that aggressive lesions often exhibit root resorption, and expansion and /or perforation of cortical bone. $^{3}$

Most common clinical manifestations include non specific pain and swelling. In many cases, the lesion is detected incidentally on radiographs. Teeth in association of the lesion are vital and may often become mobile. Radiographic appearance of CGCG is highly variable. It can occur as a unilocular or multilocular radiolucency. Periphery is usually well defined with no evidence of cortication, but in maxilla it may have ill defined ragged borders similar to that of a malignancy. Internal Structure is not present usually, occasionally granular bone organized into wispy septa may be seen. It may often displace and resorb teeth. Also, it has a strong propensity to expand cortical boundaries of mandible and maxilla. ${ }^{2}$ Radiographically, all CGCG's enlarge in a sequence of three phases:

1. Early, smaller lesions begin as a cyst like radiolucency.

2. As the lesion enlarges, adjacent areas of bone are replaced, and septa may separate adjacent lacunae of resorbed bone, thus forming a multilocular appearance.

3. Ultimately, the septa are resorbed from the most central part of the lesion towards the periphery, leaving only crenations at margin. ${ }^{1}$

Odontogenic Myxoma, Aneurysmal bone cyst, Giant cell tumor and Brown tumor of hyperparathyroidism are the differential diagnosis of such lesions.

\section{Case Report}

A 42 year old female patient reported with the chief complaint of swelling on the left side of the face since four years. It gradually increased to the present size (approximately $3 \mathrm{~cm}$ ). Patient had been taking homeopathic medication for this swelling since 2 years but there was no relief .On extra oral examination, it was found that there was a single diffuse swelling on the left middle one third of the face resulting in facial asymmetry. [Fig. 1] Intraoral swelling was present on the left side of the hard palate as well as left maxillary buccal vestibule [Fig. 2]. Overlying skin was normal and there was no rise in temperature over the swelling. On palpation, swelling was firm and non tender.There was Grade II mobility in 26 and elicited negative response on Electric Pulp Testing. The swelling was firm and non tender on palpation. 


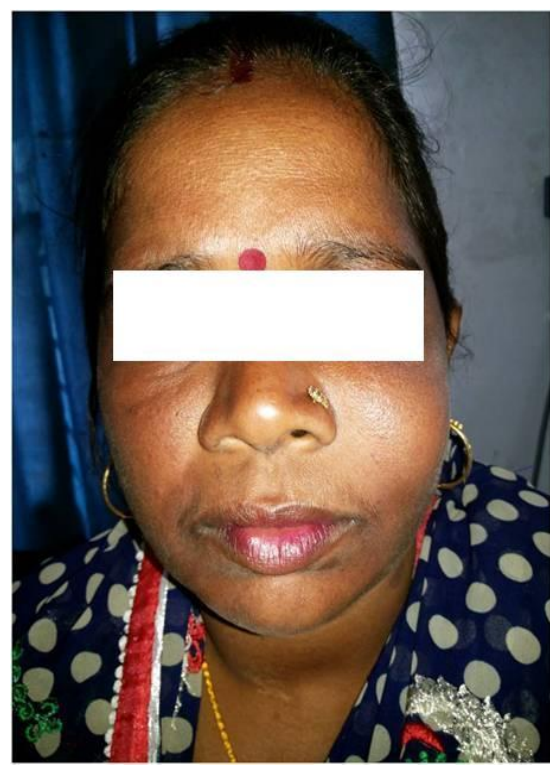

Fig. 1: Extra Oral Profile View

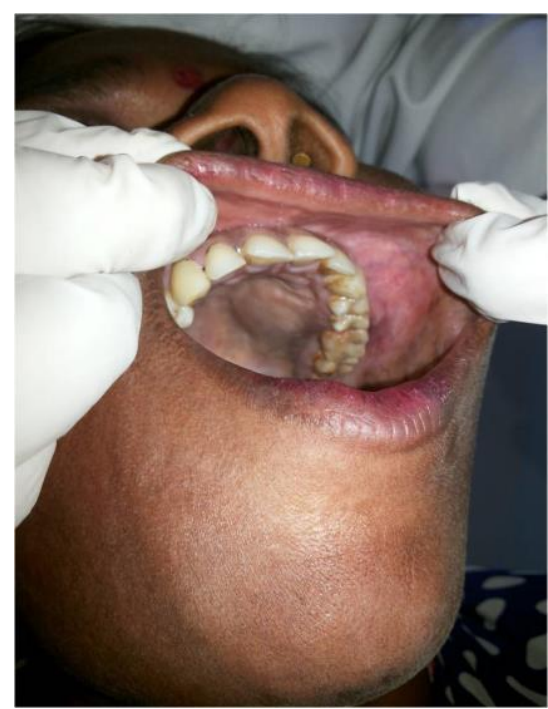

Fig. 2: Intra Oral View

An intra oral periapical radiograph (IOPA) [Fig. 3] revealed a multilocular radiolucency extending from distal aspect of 25 to distal root of 27 with spike like root resorption in 26. Maxillary lateral occlusal view [Fig. 4] revealed a large ill defined radiolucency extending from 23 to 27 with wispy ill defined septa. Panoramic view confirmed the extent of swelling from 23 to 27 with complete destruction of the inferior border of maxillary sinus on the left side. [Fig. 5] Based on the preliminary radiographic examination, a provisional diagnosis of Central Giant Cell Granuloma was made with a differential diagnosis of Odontogenic Myxoma. On performing Fine Needle Aspiration Cytology (FNAC), blood was aspirated from the lesion.

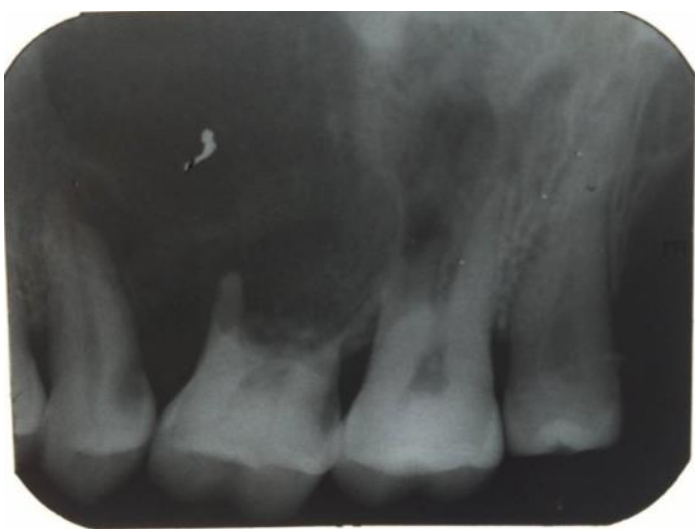

Fig. 3: Intra Oral Periapical Radiograph

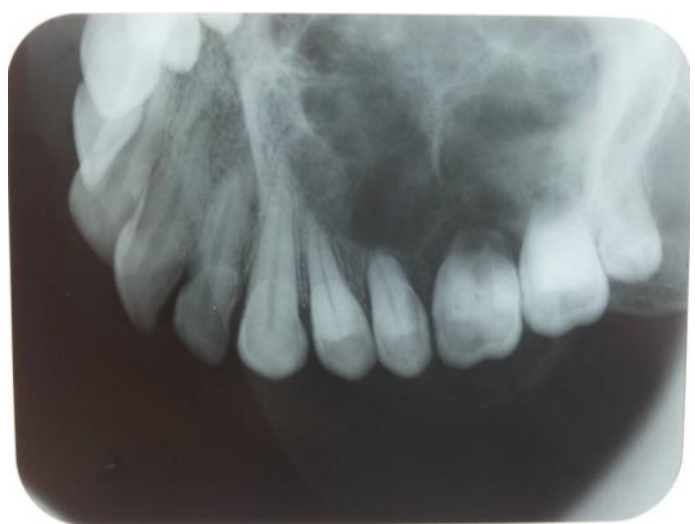

Fig. 4: Occlusal Radiograph

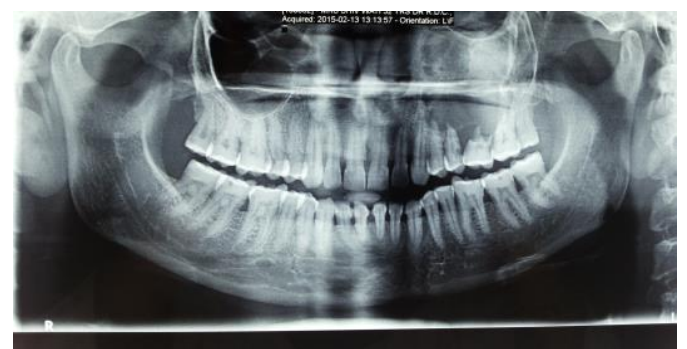

Fig. 5: Panoramic view showing radiolucency on left side

Further investigations like Computed Tomography were performed which revealed the presence of an expansile lesion of left maxillary alveolus with intact cortex projecting into the left maxillary antrum. Inferior bulging towards hard palate was also seen. [Fig. 6] 


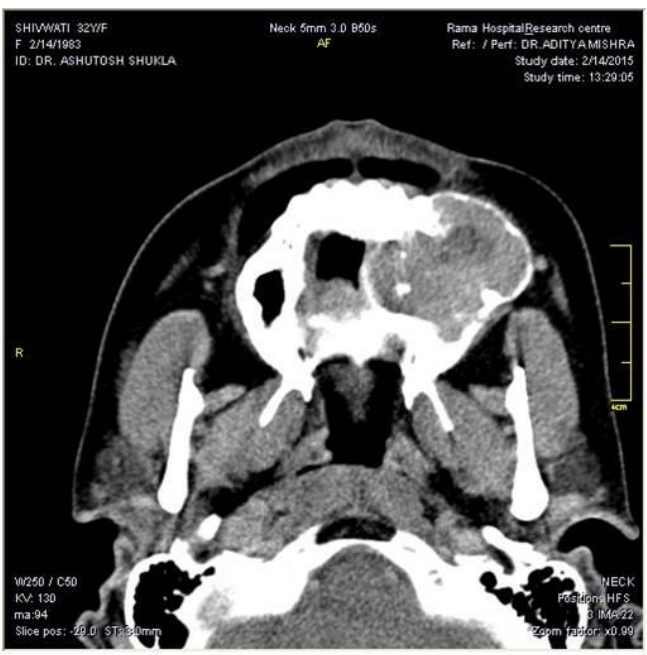

Fig. 6: CT scan image

Routine lab investigations including serum calcium, phosphorus and alkaline phosphatase were within normal limits. Hence the possibility of Brown's Tumor was ruled out. An incisional biopsy done at this stage confirmed the radiographic diagnosis of Central Giant Cell Granuloma.

Surgical enucleation and curettage was done and obturator was given to the patient. The patient recovered well as observed from subsequent follow ups. Post operative 3 months follow up. Final Histopathological Image revealed presence of spindle cells within the connective tissue stroma. The spindle cells were interspersed with multinucleated giant cells of varying shapes and sizes [Fig. 7].

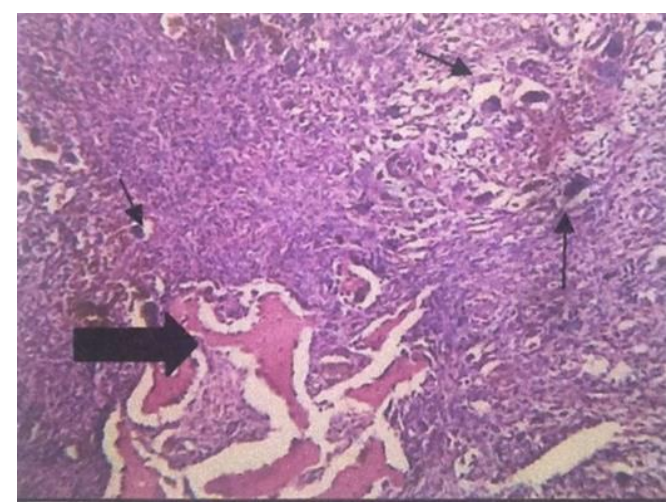

Fig. 7: Histopathological image

\section{Discussion}

Literature suggests that central giant cell granuloma occurs most commonly in young adults and diagnosed before the third decade, the site more frequently involved being the mandible. ${ }^{4}$ However in our case the patient was female, her age was 42 years, the maxilla-premolar molar region was involved, overlying mucosa was normal and maxillary sinus seemed involved and there was presence of characteristic septa which led the differential diagnosis of odontogenic myxoma.
A dilemma still exists regarding the management of this lesion, although it has been described centuries ago. ${ }^{5}$

Surgical management remains the mainstay of treatment in cases of Central Giant Cell Granuloma. Pretreatment biopsy is must. It includes enucleation and curettage, removal of peripheral bony margins and curettage. Aggressive lesions are treated by En-bloc resection leaving $0.5 \mathrm{cms}$ of margin. Recurrence rates range from $12-37 \%$.

But this type of surgical management can be disfiguring especially for females and young adults as usually the facial bones are involved. Hence non surgical approach has been advocated by some authors. ${ }^{3}$ In our case surgical treatment was preferred as the lesion was very large in size and projecting into the maxillary antrum.

Management involves intralesional injections of solution of corticosteroids. Site of injection is the area of maximum expansion i.e. area where cortical plate is thinnest. Needle is directed to inject small amount in multiple areas. Treatment is terminated when there is significant amount of resistance is caused by bone being formed and calcified. ${ }^{5}$

Calcitonin therapy involves systemic administration daily for approximately 12 months as an intradermal injection or nasal spray, which controls osteoclastogenesis. Antiangiogenic drugs like Monoclonal Abs have also been used. Alpha interferon injection works as an adjunct to surgery, has Antiangiogenic effects and inhibits bone resorption. ${ }^{1,6}$

\section{Conclusion}

Reactive lesions of bone are the most commonly occurring after odontogenic and non odontogenic cysts. Hence it is important that the general practitioner should be able to diagnose it with ease. Provisional diagnosis in such cases should only be considered after a basic radiograph. Proper diagnosis and management of such lesions is necessary to save the patient from complications such as malignant transformation, unesthetic looks /facial asymmetry.

\section{References}

1. Sholapurkar AA, Pai KM, Ahsan A. Central giant cell granuloma of the anterior maxilla. Ind $J$ Dent Res 2008;19:78-82.

2. Langland, Langlais, Nortje . Diagnostic Imaging of the Jaws $1^{\text {st }}$ ed. Williams \& Wilkins; 1995 .

3. Hegde RJ. J Ind Sot Ped Prev Dent 2004;22 (3):106- 8.

4. Burkets Oral Medicine $11^{\text {th }}$ Edition, Greenberg, Glick, Ship.

5. Metgudmath RB, Metgudmath AR, Patil SY, Sinha M. Dilemma in the management of central giant cell granuloma of maxilla. J Sci Soc 2013;40:41-3.

6. Kaban LB, Troulis MJ, Ebb D, August M, Hornicek FJ, Dodson TB. Antiangiogenic therapy with interferon alpha for giant cell lesions of the jaws. J Oral Maxillofac Surg 2002;60:1103-11. 